\title{
Mechanisms of Action of Kefir in Chronic Cardiovascular and Metabolic Diseases
}

\author{
Fabio S Pimenta ${ }^{a} \quad$ Maria Luaces-Regueira ${ }^{b} \quad$ Alyne MM Ton ${ }^{a}$ \\ Bianca P Campagnaro ${ }^{a}$ Manuel Campos-Toimil ${ }^{b}$ Thiago MC Pereira ${ }^{a, c}$ \\ Elisardo C Vasquez ${ }^{a}$
}

aLaboratory of Translational Physiology and Pharmacology, Pharmaceutical Sciences Graduate Program, Vila Velha University (UVV), Vila Velha, Brazil, bPharmacology of Chronic Diseases (CDPHARMA), Molecular Medicine and Chronic Diseases Research Centre (CIMUS), University of Santiago de Compostela, Santiago de Compostela, Spain, 'Federal Institute of Education, Science and Technology (IFES), Vila Velha, Brazil

\section{Key Words}

Microbiota - Endothelial dysfunction - Baroreflex - Insulin resistance - Hypertension • Dyslipidemia • Atherosclerosis

\begin{abstract}
The gut microbiota maintains a complex mutual interaction with different organs of the host. Whereas in normal conditions this natural community of trillions of microorganisms greatly contributes to the human health, gut dysbiosis is related with onset or worsening of diverse chronic systemic diseases. Thus, the reestablishment of gut microbiota homeostasis with consumption of prebiotics and probiotics may be a relevant strategy to prevent or attenuate several cardiovascular and metabolic complications. Among these functional foods, the synbiotic kefir, which is a fermented milk composed of a mixture of bacteria and yeasts, is currently the most used and has attracted the attention of health care professionals. The present review is focused on reports describing the feasibility of kefir consumption to provide benefits in cardiometabolic diseases, including hypertension, vascular endothelial dysfunction, dyslipidemia and insulin resistance. Interestingly, recent studies show that mechanisms of actions of kefir in cardiometabolic diseases include recruitment of endothelial progenitor cells, improvement of the balance vagal/sympathetic nervous system, diminution of excessive generation of reactive oxygen species, angiotensin converting enzyme inhibition, anti-inflammatory cytokines profile and alteration of the intestinal microbiota. These findings provide a better understanding about the mechanisms of the beneficial actions of kefir and motivate further investigations to determine whether the use of this synbiotic could also be translated into clinical improvements in cardiometabolic diseases.




\section{Cellular Physiology Cell Physiol Biochem 2018;48:1901-1914 \begin{tabular}{l|l} 
DOI: 10.1159/000492511 & and Biochemistry \\
Published online: August 8, 2018 & $\begin{array}{l}\text { O } 2018 \text { The Author(s). Published by S. Karger AG, Basel } \\
\text { www.karger.com/cpb }\end{array}$
\end{tabular} Pimenta et al.: Effects Kefir in Cardiometabolic Diseases}

\section{Introduction}

While infectious diseases were the most important health issue in the world until the beginning of the $20^{\text {th }}$ century $[1,2]$, cardiovascular and metabolic diseases gradually became the largest contributors to global morbidity and mortality, and these problems are expected to continue for at least several more decades [3]. Recent research has indicated that there is a reciprocal interaction between gut microbiota and the function of different organs of the host. The occurrence of gut dysbiosis contributes to the onset or worsening of systemic abnormalities, including cardiovascular and metabolic diseases [4, 5]. This current scenario has resulted in growing interest in the use of probiotic nutraceuticals, which are known to maintain gut homeostasis and to prevent or reverse gut dysbiosis [6-8].

Gut microbiota refers to a wide community of

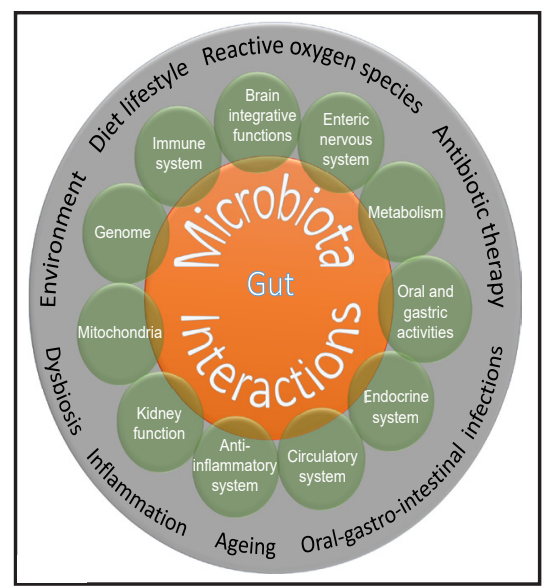

Fig. 1. Functional gut microbiota interactions and examples of disturbances leading to dysbiosis. non-pathogenic microorganisms, which co-habit with enterocytes symbiotically [4-6], providing a variety of effects on benefits to the host by creating barriers against pathogenic microorganisms by killing them, colonizing available niches, and consuming and producing nutrients besides protecting the intestinal mucosa through cellular and/or humoral mechanisms [5-7]. Evaluation of host-microbiota dynamics also suggests that the normal gut microbiota interacts with integrative brain areas of the host via components of the autonomic nervous system (enteric, afferent and efferent pathways) and with target systemic organs via circulatory and endocrine systems [8-13].

As illustrated in Fig. 1, several factors can lead to disturbance of gut microbiota (dysbiosis), including acute and chronic infections of the gastrointestinal tract, antibiotic therapy, systemic diseases, aging, diet, and lifestyle [14-17]. Here, we briefly review experimental and clinical data regarding the beneficial effects of a dairy functional food on cardiac dysautonomia, endothelial dysfunction, arterial hypertension dyslipidemia and insulin resistance, which are characteristics of cardiometabolic diseases.

\section{Functional Foods and Kefir}

Functional foods are those that provide benefits beyond basic nutrition when consumed along with the regular diet and nutraceuticals are extracts containing biologically active food components supplied in forms other than foods $[17,18]$. As a consequence of the cumulative knowledge on benefits of functional food, a growing number of investigations have been conducted to attempt to understand the mechanisms of the beneficial actions of different food components [19-22]. Therefore, we are facing a fascinating moment of significant discoveries related to the reciprocal interactions between functional foods (and nutraceuticals) and the gut microbiota $[17,18]$.

Although people commonly still consider bacteria to be disease-causing, the Nobel Laureate Elie Metchnikoff theorized the benefits of lactic acid bacteria in as early as 1910 . Currently, it is well-known that a healthy diet supplemented with functional food has healthpromoting effects on gut dysbiosis, improving the immune system and function of the body organs $[4,23]$.

Probiotics and synbiotics are already being consumed as food supplements, which are known to improve gut homeostasis [24], are safe to use and produced at low costs [8, 25]. Probiotics are biomodulators composed of live bacteria and other microorganisms that when administered in adequate amounts, are important tools expected to prevent or alleviate gut 


\section{Cellular Physiology Cell Physiol Biochem 2018:48:1901-1914 \\ and Biochemistry Published online: August 8, $2018 \quad \begin{aligned} & \text { DOI 1018 } 2018 \text { The Author(s). Published by S. Karger AG, Basel } \\ & \text { www.karger.com/cpb }\end{aligned}$ \\ Pimenta et al.: Effects Kefir in Cardiometabolic Diseases}

microbiota disturbances and confer a health benefit to the host [24-28]. Commonly used live microorganisms in probiotic products are mostly Lactobacillus, Lactococus, Streptococcus, Enterococcus, strains of gram-positive bacteria and certain yeast strains (Saccharomyces) [6, $25,28]$.

There is a growing body of evidence [28-30] that the mechanisms underlying the effects of probiotics on the host gut include (a) production of antimicrobial substances (e.g., bacteriocins, microcins, defensins, free fatty acids and hydrogen peroxide), (b) competition for adhesion to the epithelium and for nutrients, (c) immunomodulatory actions and (d) inhibition of bacterial toxin production. All of these mechanisms are currently characterized and explored as important tools to alleviate the progression of gut microbiota disturbances and dysfunction of organs in the body. In parallel, it is known that the beneficial effects of probiotics can be augmented by adding non-digestible food components, such as certain oligosaccharides (e.g., inulin, oligofructose, lactulose), which are prebiotics with enormous potential for modifying gut microbiota [8, 31,32]. Interesting, prebiotics improve the survival of probiotic microorganisms in the gastrointestinal tract with limited effect on other microorganisms [33]. Although both "synbiotic' and "symbiotic" terms have been used to describe this combination, we call "synbiotic" the synergistic blends of both prebiotics and probiotics, which are used or administered with the purpose of benefiting the health on the host. Conversely, we use the term "symbiotic" to describe different living microorganisms that live together, each obteining specific benefits from the other (symbiosis) in the gut microbiota.

The discovery that fermented milk products have positive health effects occurred several centuries ago. Kefir originated from the Northern area of the Caucasus Mountains [9, 34], and its use has spread worldwide because it is passed hand-to-hand [33, 34]. Kefir grains are constituted by a complex microbial community containing species of lactic and acetic acid bacteria and yeasts, and they are used to obtain a fermented milk named kefir [9, $34,35]$. Recent microbiological analysis of kefir grains being consumed in our region (Grand Vitoria, Brazil) [36, 37] showed a microflora formed by beneficial bacteria (e.g., Lactobacillus kefiranofaciens, Bifidobacterium) and yeasts (e.g., Candida kefir) which have been shown to preserve gut eubiosis and correct dysbiosis by adhering to gastrointestinal mucus $[31,38]$. These beneficial microbes then protect against the invasion of pathogenic microbes [7, 39, $40]$ and against the cytotoxic effects of pathogenic microbial toxins [41].

\section{Insights from Kefir Effects in Cardiovascular Diseases}

Although kefir has long been consumed worldwide based on the belief that it has beneficial effects, studies have only recently evaluated the magnitude of its protective effects in cardiovascular diseases. The first goal of our group was to determine the time course and concentration of kefir to reach a significant valuable benefit on high blood pressure (BP). Those studies were performed in spontaneously hypertensive rat (SHR) [36].

\section{Antihypertensive effects of kefir}

Different researchers have shown hypotensive effects of milk fermented with kefir grains and its derivate microorganism or biogenic compounds in experimental models of arterial hypertension [42-44]. In agreement, our laboratory reported that the probiotic kefir must be administered for at least 30 days to achieve a significant reduction of hypertensive levels $[36,45,46]$. Interestingly, this hypotensive effect of kefir was accompanied by a significant reduction in tachycardia and left ventricular hypertrophy, which are characteristics of the SHR model $[36,45,46]$. Hypotensive effects have also been observed when the milk administered was fermented by Lactobacillus fermentum [47], Lactobacillus coryniformis plus Lactobacillus gasseri [47], Lactobacillus helveticus [48], Lactobacillus paracasei [49] and Lactococcus lactis [50]. 


\section{Cellular Physiology Cell Physiol Biochem 2018:48:1901-1914

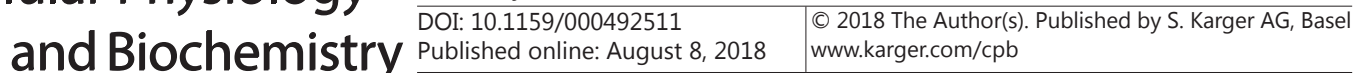 \\ Pimenta et al.: Effects Kefir in Cardiometabolic Diseases}

It is becoming clear that an important mechanism by which kefir causes a reduction of $\mathrm{BP}$ is through the inhibition of the excessive generation of reactive oxygen species (ROS) (e.g., $\mathrm{O}_{2}{ }^{-}, \mathrm{ONOO}^{-}$and $\mathrm{H}_{2} \mathrm{O}_{2}$ ) [36]. Elevated oxidative stress also contributes to the appearance and maintenance of other cardiovascular abnormalities, such as vascular inflammation, disturbed blood flow or abnormal shear stress, endothelial dysfunction, and arterial wall remodeling [51-54]. Kefir and kefir-derived bioactive products lower BP by acting as an enhancer of baroreflex sensitivity and an inhibitor of angiotensin-converting enzyme (ACE) $[43,54,55]$. Thus, kefir leads to neural and biochemical changes that contribute to decreases in BP by preventing or reversing gut dysbiosis and/or by other systemic mechanisms, as described in more detailed below.

\section{Kefir and autonomic neural control of cardiovascular function}

Our group has evaluated the effects of kefir on the abnormal autonomic control of BP and cardiac function in the SHR model. First, we investigated the basal cardiac parasympathetic (vagal) and sympathetic tone related with the control of chronotropism [56, 57]. Those data showed a decreased vagal tone and an increased sympathetic tone in the SHR, which were partially restored after the treatment with kefir for 60 days [46]. The magnitude of the kefir effect on the autonomic control of the heart was similar to that obtained by other interventions [54, 58-60]. The challenge is now to design new studies aiming to determine if the origin of the abnormality is located at central areas or peripheral nerves/receptors.

It is well-established that the baroreflex is impaired in cardiovascular and metabolic diseases, as demonstrated in the SHR model of hypertension $[36,45,46]$. Those authors, using a traditional method (see detailed description in reference [59]), evaluated the baroreflex control of arterial pressure in conscious SHR animals treated for 60 days with kefir, and the results demonstrated that kefir improved the baroreflex function [46]. Based on the pharmacological approaches used, the authors concluded that the kefir improved the baroreflex by restoring the balance between parasympathetic and sympathetic activity to the heart [46], which is in agreement with the results observed through spectral analysis of the arterial BP and heart rate (HR) [61]. However, an open question derived from the above studies is the following: by which mechanisms can probiotics and synbiotics affect brain areas? Although additional studies are required to answer this question, relevant studies suggest interactions between gut endocrine cells and vagal afferents through gut chemosensing mechanisms [5, 10]. Interestingly, in 2011, Bravo et al. demonstrated that vagotomy in mice mitigated this bidirectional communication between the central and the enteric nervous system [62]. In parallel, many researchers have demonstrated that bacteria from gut microbiota can synthesize and respond to hormones and neurotransmitters, such as acetylcholine, gamma-amino butyrate acid (GABA), serotonin and catecholamines [63]. Therefore, we speculate that the improvement in the baroreflex function and the arterial BP and HR variability in hypertensive animals could occur because kefir restores the normal gut microbiota [38] and consequently restores the production of neuroactive compounds in the intestinal lumen and subsequent effects on the bidirectional interaction gut-brain $[5,63]$.

\section{Effects of kefir on endothelial dysfunction}

In normal conditions, the endothelium maintains a balance between relaxation and contraction, but this equilibrium can be disrupted in chronic cardiovascular diseases (e.g., oxidative stress, arterial hypertension and atherosclerosis) and metabolic diseases (e.g., diabetes mellitus) [36, 64]. Physiologically, endothelial dysfunction can be easily identified via nitric oxide (NO)-dependent mechanisms when the vessel exhibits an impaired response to the gold-standard vasodilator acetylcholine and/or an exacerbated response to $\alpha 1$ vasoconstrictor agonists. Oxidative stress is a common cause of endothelial dysfunction because it can compromise NO availability and, consequently, its functionality. Hence, pharmacological and non-pharmacological (e.g., functional food therapy) therapies are relevant strategies to reduce oxidative stress. 


\section{Cellular Physiology Cell Physiol Biochem 2018;48:1901-1914 and Biochemistry Published onl00492: Aungust 8, $2018 \quad \begin{aligned} & \text { DO 2018 The Author(s). Published by S. Karger AG, Basel } \\ & \text { www.karger.com/cpb }\end{aligned}$ \\ Pimenta et al.: Effects Kefir in Cardiometabolic Diseases}

After the findings from Rashid et al. (2014) that probiotics prevented endothelial dysfunction of mesenteric artery rings in rats with common bile duct ligation [65], our group evaluated the effects of the probiotc kefir on the endothelial dysfunction in SHR [36]. The time-course of the treatment showed that at least eight weeks of treatment with kefir were required to observe a markedly beneficial effect on the endothelial dysfunction in this model of arterial hypertension [36]. The authors have demonstrated that the impaired vasodilation of aortic rings in response to acetylcholine was significantly improved by chronic treatment with kefir [36]. Additionally, kefir was able to relax the remaining contraction, which is observed when the test of vascular responsiveness to acetylcholine is repeated under conditions of pre-incubation with the NO synthase blocker L-NAME [36]. Other authors have shown that the treatment of SHR or obese animals with isolated Lactobacillus fermentum or Lactobacillus coryniformis was able to reverse the impaired aortic relaxations [66, 67], probably by the same mechanism of the synbiotic kefir (improving the balance $\cdot \mathrm{O}_{2}{ }^{-} / \mathrm{NO}$ ).

The same group of investigators has shown that kefir was also able to attenuate endothelial dysfunction in large vessels from SHR by decreasing intravascular production of $\mathrm{O}_{2}^{-}, \mathrm{ONOO}^{-} \mathrm{H}_{2} \mathrm{O}_{2}$ and restoring intravascular $\mathrm{NO}$ bioavailability $[36,45]$. In agreement, the pre-incubation of aortic rings with the inhibitor of NADPH oxidase apocynin improved the vasodilation in the SHR but not in the control group and/or in SHR kefir-treated animals [36, 67], which is clear evidence that kefir treatment could be a useful nutraceutical adjuvant for increasing NO bioavailability and decreasing ROS production. Moreover, probiotics can decrease the levels of toll-like receptor-4 (TLR4)-induced ROS and NADPH oxidase activity in that animal model of hypertension [66]. Thus, cumulative data show that kefir treatment is an effective approach for treating impaired endothelial vasodilation observed in cardiovascular diseases and involving different pathway mechanisms. Increase in contractile force to $\alpha 1$-adrenoceptor agonists is also a hallmark of chronic cardiovascular and metabolic diseases $[67,68]$. However, the effectiveness of kefir to prevent or reverse exacerbated vasoconstrictions observed in cardiovascular diseases is still an open issue.

Our research group has focused on the hypothesis that endothelial dysfunction is also linked with physical damage of the vessel layer. This possibility is corroborated by findings showing repair of the disorganization of the media layer of aorta vessels from SHR administered with milk fermented by Lactobacillus paracasei and Lactobacillus plantarum $[11,12]$. Recently, our research group demonstrated through scanning microscopy analysis that kefir was able to attenuate the injury observed on the vascular endothelial surface in SHR rats [36]. These observations suggest that although the main mechanism by which kefir improves endothelial dysfunction that accompanies the arterial hypertension is through its antioxidant effect, it also may include the recruitment of endothelial progenitor cells, as discussed below.

Although most publications have reported antioxidative properties of kefir $[11,17$, $36,43,45]$, the molecular pathways that contribute to this process remain open to further investigation. One reason this is a continuous challenge is because kefir grains contain several single chemical substances, making it difficult to magnify the relative contribution of each single molecule or micoorganism. Recently, some authors revealed that some probiotic strains present in kefir synthesize antioxidant enzymes (peroxidase, superoxide dismutase, glutathione reductase, feruloyl esterase and pseudo-catalase enzymes) and non-enzymatic substances with radical-scavenging capacities to counteract ROS [69-71]. In parallel, our group showed that the soluble non-bacterial fraction diminishes the production of prooxidant angiotensin II through the inhibition of ACE activity [54]. 


\section{Cellular Physiology Cell Physiol Biochem 2018:48:1901-1914 \\ \begin{tabular}{l|l} 
and Biochemistry Published onine: August 8, 2018 & $\begin{array}{l}\text { C } 2018 \text { The Author(s). Published by S. Karger AG, Basel } \\
\text { www.karger.com/cpb }\end{array}$
\end{tabular} \\ Pimenta et al.: Effects Kefir in Cardiometabolic Diseases}

\section{Anti-atherosclerotic and Anti-inflammatory Effects}

Complications of atherosclerosis constitute a major cause of morbidity and mortality worldwide; therefore, it is important to explore multiple options, including probiotics, for the prevention and treatment of this complex disease. The advantage for the use of probiotics is that they contain live bacteria that normally do not reside in the human gastrointestinal tract and are quickly eliminated in the feces $[72,73]$. There are studies showing that the daily consumption of kefir and kefir-derived products can result in significant hypocholesterolemic [74-76] and immunomodulatory [77-79] effects, as discussed below.

The hypocholesterolemic effect exhibited by kefir could be attributed to the microorganisms and derived biogenic compounds of this symbiotic living in the gut microbiota [72, $73,79-81]$. One of the effects of the synbiotic kefir on the gastrointestinal tract seems to involve the endogenous cholesterol metabolism pathway, ensuring its assimilation and metabolization by microorganisms, inhibiting cholesterol absorption in the small intestine [82-88]. Moreover, there are data suggesting that kefir may oppose hypercholesterolemia by 1 ) inhibition of the enzyme HMG-CoA reductase, which is a key enzyme of cholesterol synthesis $[11,86]$ and 2) the deconjugation of bile salts, increasing the demand for cholesterol for "de novo" synthesis [80, 86, 88]. In fact, a specific yeast strain into the kefir presents high levels of bile salt hydrolase activity [89], which deconjugates bile acids and increases its excretion in the feces [78, 79, 90], helping to lower cholesterol. Formulation of kefir, or biogenic compounds, plus digestive enzymes administered in hypercholesterolemic mice augments HDL and decreases LDL [76], and exhibit antiinflammatory and immunomodulatory activities [84, 85, 91, 92], corroborating the concept that probiotics and synbiotics, including kefir, are promising for treatment of dyslipidemias.

Kefir consumption results in transient changes in the levels of cytokines [92-94], TNF $\alpha$ and INF $\gamma$, in both in vivo [83, 84] and in in vitro experiments [93]. Several studies with whole kefir, kefir fractions, or organisms isolated from kefir demonstrated that anti-inflammatory cytokines promote a Th2 response while simultaneously inhibiting the pro-inflammatory Th1 response [39, 78, 92-95]. Interestingly, it was recently found that a protein derived from Lactobacillus plantarum, has a significant anti-inflammatory effect through regulating the gut barrier, microbiota and inflammatory cytokines [96].Therefore, kefir and derived isolated microorganisms can increase anti-inflammatory cytokines and decrease pro-inflammatory responses, justifying its anti-atherosclerotic potential.

The first demonstration of the anti-atherogenic properties of kefir was recently published by our research group, showing that chronic administration of the soluble nonbacterial fraction of kefir was also able to attenuate the lipid deposition in atherosclerotic mice $(\sim 100 \%)$ independently of hypercholesterolemia, which was justified by the alteration of cytokines profile [97]. These data corroborate previous findings of Uchida et al. [98], who reported a reduction of atherosclerosis in hypercholesterolemic rabbits using Lactobacillus kefiranofaciens. Thus, while treatment against atherosclerosis has been conventionally focused on hypercholesterolemia, kefir represents a valuable alternative to delay the progression of the disease by immunomodulatory effects, opening new perspectives of treatment.

\section{Benefits of Kefir on Metabolic Syndrome: Focusing on Insulin Resistance}

It is well-known that the urbanization and modern sedentary lifestyle are closely related to the increase of metabolic syndrome (MS) [99-101]. MS is characterized by a series of interlinked physiological and biochemical factors (insulin resistance, hyperglycemia, visceral adiposity, dyslipidemia, hepatic steatosis, hypertension, endothelial dysfunction, and chronic inflammation) that contribute to the increase of cardiovascular risk (2-fold), type 2 diabetes mellitus (5-fold) and all-cause mortality (1.5-fold) [99-102]. The worldwide prevalence of MS ranges from $10 \%$ to $84 \%$, depending on the region, population and other associated 


\section{Cellular Physiology Cell Physiol Biochem 2018:48:1901-1914

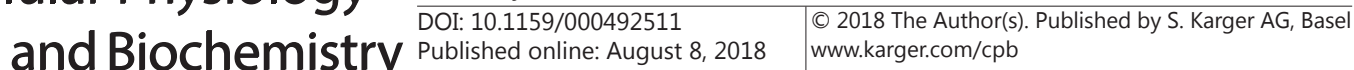 \\ Pimenta et al.: Effects Kefir in Cardiometabolic Diseases}

factors [103-105]. Obesity and insulin resistance seem to be the major predisposing factors to comorbidities, such as type 2 diabetes, cardiovascular and neurodegenerative diseases.

Although conventionally lifestyle changes and pharmacotherapy are the main strategies to control MS progression, these actions result only in partial success [33, 34]. In the last decade, it has been shown that a healthy gut microbiome helps to control obesity and insulin resistance [106-110]. The intestinal microbiome differs in lean and obese subjects and insulin-resistant patients developed an improvement in the metabolic profile after transplantation with 'healthy gut microbiota' from lean donors [108, 111]. Liou et al. [112] demonstrated that the transference of the gut microbiota from gastric bypass-treated mice to non-operated germ-free mice led to a decrease in weight and fat mass, in agreement with the suggestion that an alteration in the gut microbiota contributes to reduce MS after bariatric surgery [109]. Physiologically, it is known that the intestinal microbiome can modulate carbohydrate and lipid metabolism, hepatic glycogen and fatty storage, gut motility and appetite $[109,111]$, suggesting that the microbiota is an important adjuvant for MS treatment. These observations were confirmed in experimental fatty liver models. Kefir was capable of reducing activity of the lipogenesis pathway (fatty acid synthase and acetyl-CoA carboxylase) and increasing fatty acid oxidation by protein overexpression of phosphorylated AMP-activated protein kinase, hepatic carnitine palmitoyltransferase-1 and peroxisome proliferator-activated receptor- $\alpha$ in the liver, extending its applicability to hepatic steatosis, which is strongly associated with MS $[113,114]$. Thus, the use of probiotics and synbiotics, mainly kefir, is a promising alternative for the prevention and treatment of MS and related disorders $[89,113,114]$.

In 2002, Teruya etal. [115] reported that kefir could activate the insulin signaling pathway (possibly by activation of PI 3-kinase or other upstream molecules), culminating in the enhancement of glucose influx in skeletal muscle cells. Ten years later, an in vivo study performed by Hadisaputro et al [94]. revealed that kefir supplementation reduces glycemia and improves the balance between pro- and anti-inflammatory cytokines (IL1, IL6, TNF/IL-10 ratio) in an experimental model of type 1 diabetes [94]. These results were recently confirmed in an experimental model of MS [116]. In agreement with this study's results, Punaro et al. [117] also demonstrated antioxidative and renoprotective effects after kefir supplementation using STZ-diabetic rats. Ostadrahimi et al. [118] showed that kefir reduces glycemia and $\mathrm{HbA1c}$ in type 2 diabetes patients, suggesting that this symbiotic therapy may be an interesting adjuvant in the treatment of diabetes. Other authors have shown that kefir was able to reduce ROS intracellular levels in insulinresponsive muscle cells [117] and in STZinduced diabetes mellitus in rats [118]. In addition, proteinuria and azotemia observed in rats with type I diabetes mellitus were reduced by treatment with kefir, an effect apparently related to its antioxidant capacity [115]. Despite the above reports, there is a need for additional

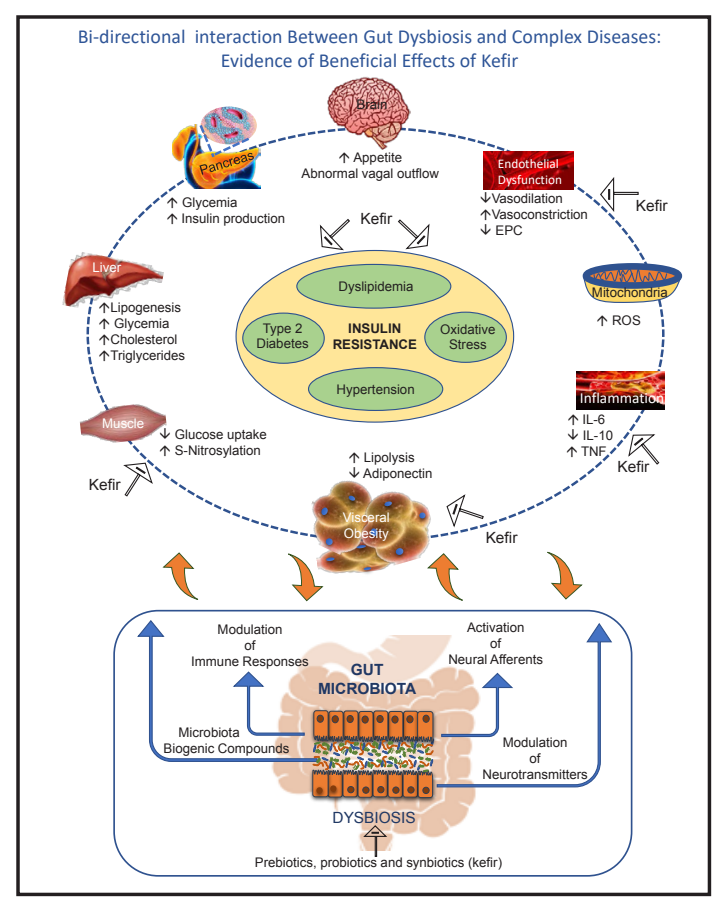

Fig. 2. Schematic illustration of the bidirectional interaction of the gut microbiota and several organs and showing beneficial effects of kefir treatment in some chronic metabolic diseases related with insulin resistance. Minus signal arrow head indicates evidence of protective effect of kefir. Abbreviations: EPC: endothelial progenitor cell, IL: interleukin, ROS: reactive oxygen species, TNF: tumor necrosis factor. 
clinical and experimental studies, including other models of arterial hypertension related with the enzymatic conversion of angiotensin I to II [119], a mechanism by which kefir may reduce high BP [54]. Fig. 2 summarizes the potential beneficial effects of kefir on different targets, highlighting the bidirectional interaction between gut microbiota and complex diseases, such as dyslipidemia, type 2 diabetes and arterial hypertension.

Finally, all of these beneficial effects of kefir on the glycemic profile deserve another point of view. It is known that gut microbiota can modulate the microbial composition of the gastrointestinal tract and the state of hunger or satiety. Interestingly, this hypothesis was recently confirmed in zebrafish, one of the most widely used animal models for developmental research [120]. After eight days of consuming probiotic Lactobacillus rhamnosus (widely present in kefir), these animals showed up-regulation and down-regulation of anorexigenic and orexigenic genes, respectively, suggesting that probiotics may regulate genes involved in glucose metabolism and appetite control [120]. Therefore, the beneficial effects of kefir in MS may be related not only to the bioavailability of its active components but also to an alteration of the intestinal microbiota.

\section{Conclusions and Perspectives}

There are several lines of evidence suggesting a bidirectional interaction between gut microbiota and the cardiovascular and metabolic diseases, influencing each other through microbiome-derived biogenic compounds, the central nervous system, the immune system, metabolic pathways, and the circulatory system. In this review, we have discussed the mechanisms of interactions between gut microbiota and cardiovascular and metabolic diseases, which include the autonomic control or the cardiac and vascular function, dyslipidemias and insulin resistance, and we suggested some mechanisms by which the synbiotic kefir appears to ameliorate those abnormalities. However, additional studies are required to verify if milk fermented by kefir grains from different origins and production processes could have similar beneficial effects. It is also expected that in the near future, analysis of the gut microbiome could be used routinely to determine the adequate prescription of synbiotic agents to patients suffering from cardiovascular and metabolic diseases.

\section{Acknowledgements}

The investigators were supported by National Council for the Development of Science and Technology (CNPq), through the grants 445736/2014-3 (BPC), 303001/2015-1 (ECV) and 445080/2014-0 (TMCP). TMCP and BPC are major contributors in writing the manuscript. AMMT, FSP and MLR helped to draft the manuscript. ECV and MCT designed and revised the manuscript. All authors read and approved the final manuscript.

\section{Disclosure Statement}

The authors declare that they have no competing interests.

\section{References}

1 Murray CJ, Lopez AD: Measuring the global burden of disease. N Engl J Med 2013;369:448-457.

2 Mensah GA, Wei GS, Sorlie PD, Fine LJ, Rosenberg Y, Kaufmann PG, Mussolino ME, Hsu LL, Addou E, Engelgau MM, Gordon D: Decline in cardiovascular mortality: Possible causes and implications. Circ Res 2017;120:366-380. 


\section{Cellular Physiology Cell Physiol Biochem 2018;48:1901-1914 \begin{tabular}{ll|l} 
and Biochemistry Published online: August 8, 2018 & $\begin{array}{l}\text { (c) } 2018 \text { The Author(s). Published by S. Karger AG, Basel } \\
\text { www.karger.com/cpb }\end{array}$
\end{tabular}}

Pimenta et al.: Effects Kefir in Cardiometabolic Diseases

3 WHO: World Health Organization. World health statistics, Geneva. 2009 http://www.who.int. Accessed 05/19/2017.

4 Claesson MJ, Clooney AG, O’Toole PW: A clinician's guide to microbiome analysis. Nat Rev Gastroenterol Hepatol 2017;14:585-595.

5 Powell N, Walker MM, Talley NJ: The mucosal immune system: master regulator of bidirectional gut-brain communications. Nat Rev Gastroenterol Hepatol 2017;14:143-159.

-6 Odenwald MA, Turner JR: The intestinal epithelial barrier: a therapeutic target? Nat Rev Gastroenterol Hepatol 2017;14:9-21.

7 Vitetta L, Saltzman ET, Nikov T, Ibrahim I, Hall S: Modulating the Gut Micro-environment in the treatment of intestinal parasites. J Clin Med 2016;5:11.

-8 Rosa D, Dias M, Grześkowiak $七$, Reis S, Conceição L, Peluzio MD: Milk kefir: nutritional, microbiological and health benefits. Nutr Res Rev 2017;30:82-96.

9 McFarland LV: From yaks to yogurt: the history, development, and current use of probiotics. Clin Infect Dis 2015;60:S85-90.

10 Noble EE, Hsu TM, Kanoski SE: Gut to Brain Dysbiosis: Mechanisms lnking western diet consumption, the microbiome, and cognitive impairment. Front Behav Neurosci 2017;11:9.

11 Prado MR, Blandón LM, Vandenberghe LP, Rodrigues C, Castro GR, Thomaz-Soccol V, Soccol CR: Milk kefir: composition, microbial cultures, biological activities, and related products. Front Microbiol 2015;6:1177.

12 Magalhães KT, de Melo Pereira GV, Campos CR, Dragone G, Schwan RF: Brazilian kefir: structure, microbial communities and chemical composition. Braz J Microbiol 2011;42:693-702.

13 Leite AM, Leite DC, Del Aguila EM, Alvares TS, Peixoto RS, Miguel MA, Silva JT, Paschoalin VM: Microbiological and chemical characteristics of Brazilian kefir during fermentation and storage processes. J Dairy Sci 2013;96:4149-4159.

14 Shen J, Obin MS, Zhao L: The gut microbiota, obesity and insulin resistance. Mol Aspects Med 2013;34:3958.

15 Lau K, Srivatsav V, Rizwan A, Nashed A, Liu R, Shen R, Akhtar M: Bridging the gap between gut microbial dysbiosis and cardiovascular diseases. Nutrients 2017;9: pii: E859.

16 Zhu Z, Xiong S, Liu D: The Gastrointestinal tract: an Initial Organ of Metabolic Hypertension? Cell Physiol Biochem 2016;38:1681-1694.

17 Pereira TM, Pimenta FS, Porto ML, Baldo MP, Campagnaro BP, Gava AL, Meyrelles SS, Vasquez EC: Coadjuvants in the diabetic complications: Nutraceuticals and drugs with pleiotropic effects. Int J Mol Sci 2016;17: pii: E1273.

18 Laparra JM, Sanz Y: Interactions of gut microbiota with functional food components and nutraceuticals. Pharmacol Res 2010;61:219-225.

19 Campos-Toimil M, Orallo F: Effects of (-)-epigallocatechin-3-gallate in $\mathrm{Ca}^{2+}$-permeable non-selective cation channels and voltage-operated $\mathrm{Ca}^{2+}$ channels in vascular smooth muscle cells. Life Sci 2007;80:2147-2153.

20 Campos-Toimil M, Elíes J, Álvarez E, Verde I, Orallo F: Effects of trans- and cis-resveratrol on $\mathrm{Ca}^{2+}$ handling in A7r5 vascular myocytes. Eur J Pharmacol 2007;577:91-99.

21 Elíes J, Cuíñas A, MacDougall DA, Leiro J, Campos-Toimil M: Trans-resveratrol down-regulates caveolin-1, up-regulates endothelial NO synthase and reduces their interaction in vascular smooth muscle and endothelial cells. Food Biosci 2013;1:31-38.

22 Segade M, Bermejo R, Silva A, Paiva-Martins F, Gil-Longo J, Campos-Toimil M: Involvement of endothelium in the vasorelaxant effects of 3, 4-DHPEA-EA and 3, 4-DHPEA-EDA, two major functional bioactives in olive oil. J Func Foods 2016;23:637-646.

23 Carding S, Verbeke K, Vipond DT, Corfe BM, Owen LJ: Dysbiosis of the gut microbiota in disease. Microb Ecol Health Dis 2015;26:26191.

24 Han C, Ding Z, Shi H, Qian W, Hou X, Lin R: The Role of probiotics in lipopolysaccharide-induced autophagy in intestinal epithelial cells. Cell Physiol Biochem 2016;38:2464-2478.

25 Parvez S, Malik KA, Ah Kang S, Kim HY: Probiotics and their fermented food products are beneficial for health. J Appl Microbiol 2006;100:1171-1185.

-26 de Barros JM, Lechner T, Charalampopoulos D, Khutoryanskiy VV, Edwards AD: Enteric coated spheres produced by extrusion/spheronization provide effective gastric protection and efficient release of live therapeutic bacteria. Int J Pharm 2015;493:483-494. 


\section{Cellular Physiology Cell Physiol Biochem 2018;48:1901-1914

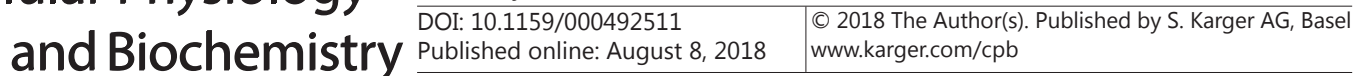

Pimenta et al.: Effects Kefir in Cardiometabolic Diseases

27 Newman D: Screening and identification of novel biologically active natural compounds. F1000Res 2017;6:783.

28 Toscano M, De Grandi R, Pastorelli L, Vecchi M, Drago L: A consumer's guide for probiotics: 10 golden rules for a correct use. Dig Liver Dis 2017;49:1177-1184 pii: S1590-8658(17)30986-6.

-29 Tune JD, Goodwill AG, Sassoon DJ, Mather KJ: Cardiovascular consequences of metabolic syndrome. Transl Res 2017;183:57-70.

-30 Dogi CA, Perdigón G: Importance of the host specificity in the selection of probiotic bacteria. J Dairy Res 2006;73:357-366.

-31 Galdeano CM, de Leblanc Ade M, Carmuega E, Weill R, Perdigón G: Mechanisms involved in the immunostimulation by probiotic fermented milk. J Dairy Res 2009;76:446-454.

-32 Gibson GR, Roberfroid MB: Dietary modulation of the human colonic microbiota: introducing the concept of prebiotics. J Nutr 1995;125:1401-1412.

33 Markowiak P, Śliżewska K: Effects of probiotics, prebiotics, and synbiotics on Human Health. Nutrients 2017;9: pii: E1021.

34 Ozen M, Dinleyici EC: The history of probiotics: the untold story. Benef Microbes 2015;6:159-165.

-35 Tamime A: Fermented milks: a historical food with modern applications - a review. Eur J Clin Nutr 2002;56:S2-S15.

-36 Friques AG, Arpini CM, Kalil IC, Gava AL, Leal MA, Porto ML, Nogueira BV, Dias AT, Andrade TU, Pereira TM, Meyrelles SS, Campagnaro BP, Vasquez EC: Chronic administration of the probiotic kefir improves the endothelial function in spontaneously hypertensive rats. J Transl Med 2015;13:390.

37 Ton AMM, Arpini CM, Campagnaro BP, Pereira TMC, Vasquez EC: Alzheimer's disease: A brief update on the influence of gut microbiota and the impact of functional food. J Food Microbiol 2018;2:11-15.

-38 Carasi P, Racedo SM, Jacquot C, Romanin DE, Serradell MA, Urdaci MC: Impact of kefir derived Lactobacillus kefiri on the mucosal immune response and gut microbiota. J Immunol Res 2015; 2015:361604.

39 Bolla PA, Abraham AG, Pérez PF, de Los Angeles Serradell M: Kefir-isolated bacteria and yeasts inhibit Shigella flexneri invasion and modulate pro-inflammatory response on intestinal epithelial cells. Benef Microbes 2016;7:103-110.

40 Kumar S, Bansal A, Chakrabarti A, Singhi S: Evaluation of efficacy of probiotics in prevention of candida colonization in a PICU-a randomized controlled trial. Crit Care Med 2013;41:565-572.

-41 Singh RK, Chang HW, Yan D, Lee KM, Ucmak D, Wong K, Abrouk M, Farahnik B,Nakamura M, Zhu TH, Bhutani T, Liao W: Influence of diet on the gut microbiome and implications for human health. J Transl Med 2017;15:73.

42 Kanbak G, Uzuner K, Kuşat Ol K, Oğlakçı A, Kartkaya K, Şentürk H: Effect of kefir and low-dose aspirin on arterial blood pressure measurements and renal apoptosis in unhypertensive rats with 4 weeks salt diet. Clin Exp Hypertens 2014;36:1-8.

43 Maeda H, Zhu X, Suzuki S, Suzuki K, Kitamura S: Structural characterization and biological activities of an exopolysaccharide kefiran produced by Lactobacillus kefiranofaciens WT-2B(T). J Agric Food Chem 2004;52:5533-5538.

-44 Yap WB, Ahmad FM, Lim YC, Zainalabidin S: Lactobacillus casei strain C1 attenuates vascular changes in spontaneously hypertensive rats. Korean J Physiol Pharmacol 2016;20:621-628.

45 Friques AG, Klippel BF, Leal MA, Kalil I, Andrade TU, Pereira TMC, Meyrelles SS, Vasquez EC: The probiotic kefir improves cardiovascular function in spontaneously hypertensive rats. The FASEB J 2015;29 Suppl 647.3.

-46 Klippel BF, Duemke LB, Leal MA, Friques AG, Dantas EM, Dalvi RF, Gava AL, Pereira TM, Andrade TU, Meyrelles SS, Campagnaro BP, Vasquez EC: Effects of kefir on the cardiac autonomic tones and baroreflex sensitivity in spontaneously hypertensive rats. Front Physiol 2016;2016;7:211.

47 Gómez-Guzmán M, Toral M, Romero M, Jiménez R, Galindo P, Sánchez M, Zarzuelo MJ, Olivares M, Gálvez J, Duarte J: Antihypertensive effects of probiotics Lactobacillus strains in spontaneously hypertensive rats. Mol Nutr Food Res 2015;59:2326-2336.

48 Chen Y, Liu W, Xue J, Yang J, Chen X, Shao Y, Kwok LY, Bilige M, Mang L, Zhang H: Angiotensin-converting enzyme inhibitory activity of Lactobacillus helveticus strains from traditional fermented dairy foods and antihypertensive effect of fermented milk of strain H9 J Dairy Sci 2014;97:6680-6692.

49 Liu CF, Tung YT, Wu CL, Lee BH, Hsu WH, Pan TM: Antihypertensive effects of Lactobacillus-fermented milk orally administered to spontaneously hypertensive rats. J Agric Food Chem 2011;59:4537-4543. 


\section{Cellular Physiology Cell Physiol Biochem 2018;48:1901-1914 \begin{tabular}{ll|l} 
DOI: 10.1159/000492511 & and Biochemistry & $\begin{array}{l}\text { O 2018 The Author(s). Published by S. Karger AG, Basel } \\
\text { www.karger.com/cpb }\end{array}$
\end{tabular} and Biochemistry Published online: August 8,2018 ,}

50 Rodríguez-Figueroa JC, González-Córdova AF, Astiazaran-García H, Vallejo-Cordoba B: Hypotensive and heart rate-lowering effects in rats receiving milk fermented by specific Lactococcus lactis strains. Br J Nutr 2013;109:827-833.

51 Nod K, Inoue T: Postprandial hyperglycemia as an etiological factor in vascular failure. Cardiovasc Diabetol 2009;8:23.

-52 Nogueira BV, Peotta VA, Meyrelles SS, Vasquez EC: Evaluation of aortic remodeling in apolipoprotein E-deficient mice and renovascular hypertensive mice. Arch Med Res 2007;38:816-821.

-53 He F, Zuo L: Redox Roles of Reactive Oxygen Species in Cardiovascular Diseases. Int J Mol Sci 2015;16:27770-27780.

54 Brasil GA, Silva-Cutini MA, Moraes FSA, Pereira TMC, Vasquez EC, Lenz D, Bissoli NS, Endringer DC, Lima EM, Biancardi VC, Maia JF, Andrade TU: The benefits of soluble non-bacterial fraction of kefir on blood pressure and cardiac hypertrophy in hypertensive rats are mediated by an increase in baroreflex sensitivity and decrease in angiotensin-converting enzyme activity. Nutrition 2018;51-52:66-72.

55 Jiang Y, Yang W, Du F, Yao Y, Shi C, Wang C: Effective treatment of hypertension by recombinant Lactobacillus plantarum expressing angiotensin converting enzyme inhibitory peptide. Microb Cell Fact 2015;14:202.

56 Campagnaro BP, Gava AL, Meyrelles SS, Vasquez EC: Cardiac-autonomic imbalance and baroreflex dysfunction in the renovascular Angiotensin-dependent hypertensive mouse. Int J Hypertens 2012:968123.

57 Campagnaro BP, Tonini CL, Nogueira BV, Casarini DE, Vasquez EC, Meyrelles SS: DNA damage and augmented oxidative stress in bone marrow mononuclear cells from Angiotensin-dependent hypertensive mice. Int J Hypertens 2013; 2013:305202.

-58 Dias da Silva VJ, Viana Públio CC, de Melo Alves R, Fazan R Jr, Ruscone TG, Porta A, Malliani A, Salgado HC, Montano N: Intravenous amiodarone modifies autonomic balance and increases baroreflex sensitivity in conscious rats. Auton Neurosci 2002;95:88-96.

59 Vasquez EC, Peotta VA, Meyrelles SS: Cardiovascular autonomic imbalance and baroreflex dysfunction in the apolipoprotein E-deficient mouse. Cell Physiol Biochem 2012;29:635-646.

60 de Moura-Tonello SC, Porta A, Marchi A, de Almeida Fagundes A, Francisco C de O, Rehder-Santos P, MilanMattos JC, Simões RP, Gois Mde 0, Catai AM: Cardiovascular variability analysis and baroreflex estimation in patients with type 2 diabetes in absence of any manifest neuropathy. PLoS One 2016;11(3):e0148903.

61 Su DF, Miao CY: Reduction of blood pressure variability: a new strategy for the treatment of hypertension. Trends Pharmacol Sci 2005;26:388-390.

62 Bravo JA, Forsythe P, Chew MV, Escaravage E, Savignac HM, Dinan TG, Bienenstock J, Cryan JF: Ingestion of Lactobacillus strain regulates emotional behavior and central GABA receptor expression in a mouse via the vagus nerve.Proc Natl Acad Sci USA 2011;108:16050-16055.

63 Bonaz B, Bazin T, Pellissier S: The Vagus nerve at the Interface of the microbiota-gut-brain axis. Front Neurosci 2018;12:49.

64 Leal MAS, Dias AT, Porto ML, Brun BF, Gava AL, Meyrelles SS, Gil-Longo J,Campos-Toimil M, Pereira TMC, Vasquez EC: Sildenafil (Viagra ${ }^{\circledR}$ ) prevents cox-1/TXA2 pathway-mediated vascular hypercontractility in ApoE-/- mice. Cell Physiol Biochem 2017;44:1796-1809.

65 Rashid SK, Idris-Khodja N, Auger C, Alhosin M, Boehm N, Oswald-Mammosser M, Schini-Kerth VB: Probiotics (VSL\#3) prevent endothelial dysfunction in rats with portal hypertension: Role of the angiotensin system. PLoS One 2014;9(5):e97458

66 Gómez-Guzmán M, Toral M, Romero M, Jiménez R, Galindo P, Sánchez M, Zarzuelo MJ, Olivares M, Gálvez J, Duarte J: Antihypertensive effects of probiotics Lactobacillus strains in spontaneously hypertensive rats. Mol Nutr Food Res 2015;59:2326-2336.

67 Toral M, Gómez-Guzmán M, Jiménez R, Romero M, Sánchez M, Utrilla MP, Garrido-Mesa N, RodríguezCabezas ME, Olivares M, Gálvez J, Duarte J: The probiotic Lactobacillus coryniformis CECT5711 reduces the vascular pro-oxidant and pro-inflammatory status in obese mice. Clin Sci (Lond) 2014;127:33-45.

68 Fahning BM, Dias AT, Oliveira JP, Gava AL, Porto ML, Gomes IB, Nogueira BV, Campagnaro BP, Pereira TM, Vasquez EC, Balarini CM, Meyrelles SS: Sildenafil improves vascular endothelial structure and function in renovascular hypertension. Curr Pharm Biotechnol 2015;16:823-831.

-69 Tang W, Li C, He Z, Pan F, Pan S, Wang Y: Probiotic properties and cellular antioxidant activity of Lactobacillus plantarum MA2 isolated from Tibetan kefir grains. Probiotics Antimicrob Proteins 2017 DOI:10.1007/s12602-017-9349-8. 


\section{Cellular Physiology Cell Physiol Biochem 2018;48:1901-1914 \begin{tabular}{ll|l} 
and Biochemistry Published onlıne: August 8, 2018 & $\begin{array}{l}\text { (c) } 2018 \text { The Author(s). Published by S. Karger AG, Basel } \\
\text { www.karger.com/cpb }\end{array}$
\end{tabular}}

70 Cavalcanti Neto MP, Aquino JS, Romão da Silva LF, de Oliveira Silva R, Guimarães KSL, de Oliveira Y, de Souza EL, Magnani M, Vidal H, de Brito Alves JL: Gut microbiota and probiotics intervention: A potential therapeutic target for management of cardiometabolic disorders and chronic kidney disease? Pharmacol Res 2018;pii: S1043-6618(17)31050-2.

-71 Calderini E, Celebioglu HU, Villarroel J, Jacobsen S, Svensson B, Pessione E: Comparative proteomics of oxidative stress response of Lactobacillus acidophilus NCFM reveals effects on DNA repair and cysteine de novo synthesis. Proteomics 2017;17: doi: 10.1002.

72 St-Onge MP, Farnworth ER, Savard T, Chabot D, Mafu A, Jones PJ: Kefir consumption does not alter plasma lipid levels or cholesterol fractional synthesis rates relative to milk in hyperlipidemic men: a randomized controlled trial [ISRCTN10820810]. BMC Complement Altern Med 2002;2:1.

-73 St-Onge MP, Farnworth ER, Jones PJ: Consumption of fermented and nonfermented dairy products: effects on cholesterol concentrations and metabolism. Am J Clin Nutr 2000;71:674-1681.

74 Ooi LG, Liong MT: Cholesterol-lowering effects of probiotics and prebiotics: a review of in vivo and in vitro findings. Int J Mol Sci 2010;11:2499-522.

75 Ichim TE, Patel AN, Shafer KA: Experimental support for the effects of a probiotic/digestive enzyme supplement on serum cholesterol concentrations and the intestinal microbiome. J Transl Med 2016;14(1):184.

76 Huang Y, Wu F, Wang X, Sui Y, Yang L, Wang J: Characterization of Lactobacillus plantarum Lp27 isolated from Tibetan kefir grains: a potential probiotic bacterium with cholesterol-lowering effects. J Dairy Sci 2013;96:2816-2825.

77 Taverniti V, Minuzzo M, Arioli S, Junttila I, Hämäläinen S, Turpeinen H, Mora D, Karp M, Pesu M, Guglielmetti S: In vitro functional and immunomodulatory properties of the Lactobacillus helveticus MIMLh5Streptococcus salivarius ST3 association that are relevant to the development of a pharyngeal probiotic product. Appl Environ Microbiol 2012;78:4209-4216.

78 Vinderola CG, Medici M, Perdigón G: Relationship between interaction sites in the gut, hydrophobicity, mucosal immunomodulating capacities and cell wall protein profiles in indigenous and exogenous bacteria. J Appl Microbiol 2004;96:230-243.

79 Vinderola CG, Duarte J, Thangavel D, Perdigón G, Farnworth E, Matar C: Immunomodulating capacity of kefir. J Dairy Res 2005;72:195-202.

80 Xiao JZ, Kondo S, Takahashi N, Miyaji K, Oshida K, Hiramatsu A, Iwatsuki K, Kokubo S, Hosono A: Effects of milk products fermented by Bifidobacterium longum on blood lipids in rats and healthy adult male volunteers. J Dairy Sci 2003;86:2452-2461.

81 Vujičić IF, Vulić M, Könyves T: Assimilation of cholesterol in milk by kefir cultures. Biotechnol Lett 1992;14:847-850.

-82 Hosono A, Tanako T: Binding of cholesterol with lactic acid bacterial cells. Milchwiss 1995;50:556-560.

83 Yoon YH, Cho JK, Baek YJ, Huh CS::Antimutagenic activity of Lactobacillus spp. isolated from kefir and yoghurt and non-starter strains. Korean J Animal Sci 1999;41:39-44.

84 Guo Z, Liu XM, Zhang QX, Shen Z, Tian FW, Zhang H, Sun ZH, Zhang HP, Chen W: Influence of consumption of probiotics on the plasma lipid profile: a meta-analysis of randomised controlled trials. Nutr Metab Cardiovasc Dis 2011;201;21:844-850.

85 Wang LX, Liu K, Gao DW, Hao JK: Protective effects of two Lactobacillus plantarum strains in hyperlipidemic mice. World J Gastroenterol 2013;19:3150-3156.

-86 Wang Y, Xu N, Xi A, Ahmed Z, Zhang B, Bai X: Effects of Lactobacillus plantarum MA2 isolated from Tibet kefir on lipid metabolism and intestinal microflora of rats fed on high-cholesterol diet. Appl Microbiol Biotechnol 2009;84:341-347.

87 Zheng Y, Lu Y, Wang J, Yang L, Pan C, Huang Y: Probiotic properties of Lactobacillus strains isolated from Tibetan kefir grains. PLoS One 2013;8(7):e69868.

88 Liu Y, Fatheree NY, Mangalat N, Rhoads JM: Lactobacillus reuteri strains reduce incidence and severity of experimental necrotizing enterocolitis via modulation of TLR4 and NF- $\kappa B$ signaling in the intestine. Am J Physiol Gastrointest Liver Physiol 2012;302:G608-617.

89 Liu JR, Wang SY, Chen MJ, Chen HL, Yueh PY, Lin CW: Hypocholesterolaemic effects of milk-kefir and soyamilk-kefir in cholesterol-fed hamsters. Br J Nutr 2006;95(5):939-946 doi: 10.1079/BJN20061752.

-90 Delzenne NM, Neyrinck AM, Bäckhed F, Cani PD: Targeting gut microbiota in obesity: effects of prebiotics and probiotics. Nat Rev Endocrinol 2011;7:639-646. 


\section{Cellular Physiology Cell Physiol Biochem 2018;48:1901-1914 \begin{tabular}{l|l|l} 
DOI: 10.1159/000492511 & 2018 & $\begin{array}{l}\text { O 2018 The Author(s). Published by S. Karger AG, Basel } \\
\text { www.karger.com/cpb }\end{array}$
\end{tabular}}

91 Macfarlane GT, Macfarlane S: Human colonic microbiota: ecology, physiology and metabolic potential of intestinal bacteria. Scand J Gastroenterol Suppl 1997;222:3-9.

-92 Vinderola G, Perdigon G, Duarte J, Farnworth E, Matar C: Effects of the oral administration of the exopolysaccharide produced by Lactobacillus kefiranofaciens on the gut mucosal immunity. Cytokine 2006;36:254-260.

-93 Carasi P, Racedo SM, Jacquot C, Romanin DE, Serradell MA, Urdaci MC: Impact of kefir derived Lactobacillus kefiri on the mucosal immune response and gut microbiota. J Immunol Res 2015;2015:361604.

$\$ 94$ Hadisaputro S, Djokomoeljanto RR, Judiono, Soesatyo MH: The effects of oral plain kefir supplementation on proinflammatory cytokine properties of the hyperglycemia Wistar rats induced by streptozotocin. Acta Med Indones 2012;44:100-104.

-95 Bourrie BC, Willing BP, Cotter PD: The microbiota and health promoting characteristics of the fermented beverage kefir. Front Microbiol 2016;7:647.

-96 Yin M, Yan X, Weng W, Yang Y, Gao R, Liu M, Pan C, Zhu Q, Li H, Wei Q, Shen T, Ma Y, Qin H: Micro integral membrane protein (MIMP), a newly discovered anti-Inflammatory protein of Lactobacillus plantarum, enhances the gut barrier and modulates microbiota and inflammatory cytokines. Cell Physiol Biochem 2018;45:474-490.

-97 Santanna AF, Filete PF, Lima EM, Porto ML, Meyrelles SS, Vasquez EC, Endringer DC, Lenz D, Abdalla DS, Pereira TM, Andrade TU: Chronic administration of the soluble, nonbacterial fraction of kefir attenuates lipid deposition in LDLr(-/-) mice. Nutrition 2017;35:100-105.

$\$ 98$ Uchida M, Ishii I, Inoue C, Akisato Y, Watanabe K, Hosoyama S, Toida T, Ariyoshi N, Kitada M: Kefiran reduces atherosclerosis in rabbits fed a high cholesterol diet. J Atheroscler Thromb 2010;17:980-988.

-99 Alberti KG, Zimmet P, Shaw J; IDF Epidemiology Task Force Consensus Group: The metabolic syndrome: a new worldwide definition. Lancet 2005;366:1059-1062.

100 Galassi A, Reynolds K, He J: Metabolic syndrome and risk of cardiovascular disease: a meta-analysis. Am J Med 2006;119:812-819.

101 Pucci G, Alcidi R, Tap L, Battista F, Mattace-Raso F, Schillaci G: Sex- and gender-related prevalence, cardiovascular risk and therapeutic approach in metabolic syndrome: A review of the literature. Pharmacol Res 2017;120:34-42.

102 Mottillo S, Filion KB, Genest J, Joseph L, Pilote L, Poirier P, Rinfret S, Schiffrin EL, Eisenberg MJ: The metabolic syndrome and cardiovascular risk a systematic review and meta-analysis. J Am Coll Cardiol 2010;56:1113-1132.

103 Kaur J: A comprehensive review on metabolic syndrome. Cardiol Res Pract 2014;2014:943162.

104 Ritchie SA, Connell JM: The link between abdominal obesity, metabolic syndrome and cardiovascular disease. Nutr Metab Cardiovasc Dis 2007;17:319-326.

105 Desroches S, Lamarche B: The evolving definitions and increasing prevalence of the metabolic syndrome. Appl Physiol Nutr Metab 2007;32:23-32.

106 Rosenstock J: Reflecting on type 2 diabetes prevention: more questions than answers! Diabetes Obes Metab 2007;9:S3-11.

107 Putignani L, Del Chierico F, Petrucca A, Vernocchi P, Dallapiccola B: The human gut microbiota: a dynamic interplay with the host from birth to senescence settled during childhood. Pediatr Res 2014;76:2-10.

108 Turnbaugh PJ, Ley RE, Mahowald MA, Magrini V, Mardis ER, Gordon JI: An obesity-associated gut microbiome with increased capacity for energy harvest. Nature 2006;444:1027-1031.

109 Parekh PJ, Balart LA, Johnson DA: The influence of the gut microbiome on obesity, metabolic syndrome and Gastrointestinal Disease. Clin Transl Gastroenterol 2015;6:e91.

110 Lloyd-Price J, Abu-Ali G, Huttenhower C: The healthy human microbiome. Genome Med 2016;8:51.

111 Festi D, Schiumerini R, Eusebi LH, Marasco G, Taddia M, Colecchia A: Gut microbiota and metabolic syndrome. World J Gastroenterol 2014;20:16079-16094.

112 Liou AP, Paziuk M, Luevano JM Jr, Machineni S, Turnbaugh PJ, Kaplan LM: Conserved shifts in the gut microbiota due to gastric bypass reduce host weight and adiposity. Sci Transl Med 2013;5(178):178ra41.

113 Chen HL, Tung YT, Tsai CL, Lai CW, Lai ZL, Tsai HC, Lin YL, Wang CH, Chen CM: Kefir improves fatty liver syndrome by inhibiting the lipogenesis pathway in leptin-deficient ob/ob knockout mice. Int J Obes (Lond) 2014;38:1172-1179. 


\section{Cellular Physiology Cell Physiol Biochem 2018;48:1901-1914

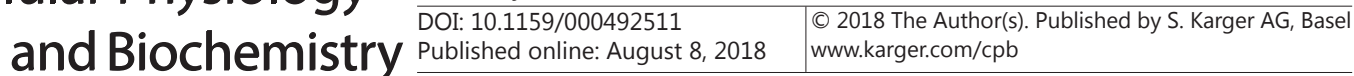

Pimenta et al.: Effects Kefir in Cardiometabolic Diseases

114 Tung YT, Chen HL, Wu HS, Ho MH, Chong KY, Chen CM: Kefir peptides prevent hyperlipidemia and obesity in high-fat-diet-induced obese rats via lipid metabolism modulation. Mol Nutr Food Res 2018 Feb;62: doi: 10.1002.

115 Teruya K, Yamashita M, Tominaga R, Nagira T, Shim SY, Katakura Y, Tokumaru S, Tokumaru K, Barnes D, Shirahata S: Fermented milk, Kefram-Kefir enhances glucose uptake into insulin-responsive muscle cells. Cytotechnology 2002; 40:107-716.

116 Rosa DD, Grześkowiak ŁM, Ferreira CL, Fonseca AC, Reis SA, Dias MM, Siqueira NP, Silva LL, Neves CA, Oliveira LL, Machado AB, Peluzio Mdo C: Kefir reduces insulin resistance and inflammatory cytokine expression in an animal model of metabolic syndrome. Food Funct 2016;7:3390-3401.

-117 Punaro GR, Maciel FR, Rodrigues AM, Rogero MM, Bogsan CS, Oliveira MN, Ihara SS, Araujo SR, Sanches TR, Andrade LC, Higa EM: Kefir administration reduced progression of renal injury in STZ-diabetic rats by lowering oxidative stress. Nitric Oxide 2014;37:53-60.

118 Ostadrahimi A, Taghizadeh A, Mobasseri M, Farrin N, Payahoo L, Beyramalipoor Gheshlaghi Z, Vahedjabbari M: Effect of probiotic fermented milk (kefir) on glycemic control and lipid profile in type 2 diabetic patients: a randomized double-blind placebo-controlled clinical trial. Iran J Public Health 2015;44:228237.

119 Nogueira BV, Palomino Z, Porto ML, Balarini CM, Pereira TM, Baldo MP, Casarini DE, Meyrelles SS, Vasquez EC: Granulocyte colony stimulating factor prevents kidney infarction and attenuates renovascular hypertension. Cell Physiol Biochem 2012;29:143-152.

-120 Falcinelli S, Rodiles A, Unniappan S, Picchietti S, Gioacchini G, Merrifield DL, Carnevali O: Probiotic treatment reduces appetite and glucose level in the zebrafish model. Sci Rep 2016;6:18061. 